$x=1$ indicates perfect consistency and $x \leqslant 0$ complete inconsistency.

When a gold standard is present the validity of every reviewer can be studied. The observed validity (OV)that is, the proportion of correct diagnoses-must be compared with the chance validity $(\mathrm{CV})$, where $\mathrm{CV}=$ $(\mathrm{EP})(\mathrm{P})+(1-\mathrm{EP})(1-\mathrm{P})$ and $\mathrm{P}$ is the real prevalence. When $\mathrm{EP} \triangleq \mathrm{P}, \mathrm{CV}=2(\mathrm{EP}-0.5)^{i}+0.5$.

A simple overall measure for diagnostic validity is $(\mathrm{OV}-\mathrm{CV}):(1-\mathrm{CV})$. Because validity is more important than consistency it is named iota (I), one letter before kappa in the Greek alphabet. Iota among patients with disease is $\mathrm{I}($ sensitivity $)=(\mathrm{OSE}-\mathrm{EP}):(1-\mathrm{EP})$, in which OSE stands for the observed sensitivity. Iota among those without disease is $\mathrm{I}$ (specificity $)=(\mathrm{OSP}-(1-\mathrm{EP})):(1-(1-\mathrm{EP}))$, in which OSP stands for the observed specificity. $I=1$ indicates perfect validity and $I \leqslant 0$ no validity at all beyond chance validity.

1 Guyton AC. Textbook of medical physiology. Philadelphia: Saunders, 1981:603. 2 Brand A. Diagnostische Aussenseitermethoden. Deutsche Medizinische Wochenschrift 1983;108:870-6.

3 Dern N. Uber die Irisdiagnostik [Dissertation]. Marburg: Philipps Universität, 1984

4 Berggren L. Iridology. A critical review. Acta Ophthalmologica 1985;63:1-8. 5 Feinstein AR. Clinical epidemiology. The architecture of clinical research. Philadelphia: Saunders, 1985.

6 Knipschild P. Iota voor de diagnostische validiteit. Tijdschrift voor Sociale Gezondheidszorg 1987;65:754-5.

7 Schouten HJA. Statistical measurement of interobserver agreement [Dissertation] Rotterdam: Erasmus Universiteit, 1985.

Jongedijk J. Iriscopie. Bres 1973;43:38-53.

9 Simon A, Worthen DM, Mitas JA. An evaluation of iridology. JAMA Simon A, Worthen

(Accepted 5 October 1988)

\title{
Aluminium accumulation and immunosuppressive effect in recipients of kidney transplants
}

\author{
K P Nordal, E Dahl, D Albrechtsen, J Halse, T Leivestad, S Tretli, A Flatmark
}

\begin{abstract}
Aluminium that has accumulated in the body is thought to have a generalised cytotoxic effect. A prospective study of aluminium accumulation in bone-that is, subclinical aluminium toxicitywas carried out in 94 recipients of kidney allografts, who were followed up for three years. Subclinical aluminium toxicity was found in 66 patients. A significantly smaller proportion of patients with aluminium accumulation experienced a rejection episode: $30(58 \%) v 12(86 \%)$ who received grafts from cadavers and $4(29 \%) v 10(71 \%)$ who received grafts from living donors. On multivariate analysis only the source of the kidney and aluminium accumulation were found to influence the rejection rate.
\end{abstract}

These findings suggest that aluminium accumulation has an immunosuppressive effect.

\section{Introduction} end stage chronic renal failure. ${ }^{\prime 2}$ Aluminium toxicity is indicated by the accumulation of aluminium in bone and by symptoms and signs from several organs. ${ }^{3+}$ The

Departments of Medicine,

and Pathology,

Rikshospitalet, 0027 Oslo 1, Norway

K P Nordal, MD, registrar in medicine

$\mathrm{E}$ Dahl, MD, research fellow in surgery and pathology

D Albrechtsen, MD,

consultant in surgery

$\mathrm{J}$ Halse, $\mathrm{MD}$, consultant in

medicine

A Flatmark, MD, professor of surgery

\section{Institute of}

Transplantation

Immunology,

Rikshospitalet, 0027 Oslo 1

$\mathrm{T}$ Leivestad, MD, registrar

\section{Norwegian Cancer}

Registry,

0310 Oslo 3

$S$ Tretli, CANDREAL, epidemiologist

Correspondence to: $\mathrm{Dr}$ Nordal. remains to be elucidated. We report a prospective study of aluminium accumulation in recipients of kidney transplants and its relation to immune events after transplantation.

\section{Patients and methods}

We studied 94 adult patients, who gave their informed consent to participate and received a kidney graft from a cadaver $(n=66)$ or a living donor identical for histocompatibility antigens $(n=28)$ during one year (1983-4). They represented $83 \%$ of all patients eligible for study. Patients who received a cadaveric transplant were selected on the basis of medical urgency, waiting time, and a negative result of a cross matching test against donor $\mathrm{T}$ cells. Blood transfusions were given for medical reasons only. The patients' immune systems were suppressed by a uniform regimen that included cyclosporin and steroids. ${ }^{6}$ Rejection episodes were treated by intravenous bolus doses of methylprednisolone. ${ }^{6}$ All patients were followed up for three years.
Aluminium accumulation is a potential hazard of

Rejection episodes were defined by a rise in serum creatinine concentration not explained by nonimmunological complications as shown by renography, sonography, computed tomography, monitoring of cyclosporin concentrations, and intravenous pyelography or angiography; improved renal function after treatment for rejection; or results of renal biopsy. Non-functioning grafts were monitored by fine needle aspiration cytology.

Randomly chosen sections of a specimen of transiliac bone obtained during the transplant operation were stained with aurin tricarboxylic acid and Prussian blue. Aluminium accumulation was said to be present if the aurin tricarboxylic acid stain was positive ${ }^{7}$ and the Prussian blue stain negative. Histochemical staining for aluminium is usually negative unless the aluminium content in bone exceeds $50 \mathrm{mg} / \mathrm{kg}$ dry weight ( 10 times the normal concentration). ${ }^{8}$

Wilcoxon two sample tests and Fisher's exact tests were used to test differences between groups. One sided Fisher's exact tests were used as aluminium is known to have toxic effects only in biological systems. Log rank tests were used to test differences in survival rates. Multivariate analyses were performed to test simultaneously the influence on the rejection rate of several factors existing before transplantation. This was done with a logistic model and generalised linear interactive modelling ${ }^{9}$ - that is, a logit analysis as all covariates were categorised.

\section{Results}

Aluminium accumulation was found in 52 (79\%) patients who received kidneys from cadavers and 14 $(50 \%)$ patients who received kidneys from living donors (table I). Age, histocompatibility matching, and the proportion of patients previously given transfusions or dialysis were similar in patients positive and negative for aluminium.

One and three year survival rates of patients were $89 \%$ and $76 \%$ for recipients of kidneys from cadavers and $100 \%$ for recipients of kidneys from living donors, with no difference between groups of patients positive and negative for aluminium. One and three year survival rates of grafts were $73 \%$ and $62 \%$ for kidneys from cadavers and $96 \%$ and $82 \%$ for kidneys from living donors. Patients positive for aluminium tended to have better graft survival than patients negative for aluminium, but the difference was not significant. 
TABLE I-Aluminium accumulation before kidney transplantation and age of patients, histocompatibility of graft, prevalence of transfusion and dialysis before transplantation, graft survival, and occurrence of rejection episodes according to whether kidney was from a cadaver or living donor

\begin{tabular}{|c|c|c|c|c|}
\hline & \multicolumn{2}{|c|}{ Kidney from cadaver } & \multicolumn{2}{|c|}{ Kidney from living donor } \\
\hline & $\begin{array}{l}\text { Aluminium staining } \\
\text { positive }(\mathrm{n}=52)\end{array}$ & $\begin{array}{l}\text { Aluminium staining } \\
\text { negative }(n=14)\end{array}$ & $\begin{array}{l}\text { Aluminium staining } \\
\text { positive }(n=14)\end{array}$ & $\begin{array}{l}\text { Aluminium staining } \\
\text { negative }(n=14)\end{array}$ \\
\hline Mean age (years) & $50 \cdot 4$ & $50 \cdot 2$ & $27 \cdot 4$ & $32 \cdot 1$ \\
\hline Mean No of HLA-A or B mismatches & $2 \cdot 4$ & $2 \cdot 5$ & 1.9 & $1 \cdot 4$ \\
\hline Mean No of HLA-DR mismatches & $1 \cdot 0$ & $0 \cdot 8$ & $0 \cdot 8$ & $0 \cdot 6$ \\
\hline No $(\%)$ of patients given blood transfusion & $45 \quad(87)$ & $8 \quad(57)$ & $12 \quad(86]$ & $8 \quad(57)$ \\
\hline No $(\%)$ of patients given dialysis & $47 \quad(90)$ & $10(71)$ & $12(86)$ & $8 \quad(57)$ \\
\hline No $(\%)$ of grafts surviving at one year & $40 \quad(77)$ & $8 \quad(57)$ & $14(100)$ & $13 \quad(93)$ \\
\hline No $(\%)$ of grafts surviving at three years & $33(63)$ & $8 \quad 57)$ & $13(93)$ & $10 \quad(71)$ \\
\hline $\begin{array}{l}\text { No }(\%) \text { of patients who had rejection episode(s) } \\
\text { in first year after transplantation }\end{array}$ & $30(58)^{\star}$ & $12 \quad(86)$ & $4(29)^{\star \star}$ & $10 \quad(71)$ \\
\hline
\end{tabular}

${ }^{\star} \mathrm{p}=0 \cdot 048 ;{ }^{\star \star} \mathrm{p}=0 \cdot 029$

TABLE II - Deviance between observed and estimated rejection rates in multivariate analyses

\begin{tabular}{lcc}
\hline Variables included in model & Deviance & $\begin{array}{c}\text { Degrees } \\
\text { of freedom }\end{array}$ \\
\hline Donor + aluminium + dialysis + transfusion & $13 \cdot 52$ & 10 \\
Donor + aluminium + transfusion & $13 \cdot 57$ & 11 \\
Donor + aluminium & $14 \cdot 48$ & 12 \\
Donor + dialysis + transfusion & $20 \cdot 45$ & 11 \\
\hline
\end{tabular}

*Cadaver or living donor; aluminium accumulation present or absent dialysis given before transplantation or not given; transfusion given before transplantation or not given.

Graft rejection was the main cause of early graft loss, causing 14 of the 19 losses during the first year.

A rejection episode occurred during the first year in $42(63 \%)$ patients who received kidneys from cadavers and $14(50 \%)$ who received kidneys from living donors. A significantly smaller proportion of patients positive than negative for aluminium had a rejection episode: $30(58 \%) v 12(86 \%)$ recipients of grafts from cadavers $(\mathrm{p}=0.048)$ and $4(29 \%) v 10(71 \%)$ recipients of grafts from living donors $(p=0.029)$. The rejection rate was not associated with age, histocompatibility matching, blood transfusions before transplantation, or dialysis.

An acceptable deviance between observed and estimated rejection rates was found by multivariate analysis of several models that included various combinations of variables (table II). An acceptable fit relative to the degree of freedom was observed in a model that included only the donor source and aluminium accumulation, whereas the model that did not take aluminium accumulation into account fitted poorly.

The risk of rejection of a graft from a cadaver was $3 \cdot 2$ times higher than the risk of rejection of a graft from a living donor ( $95 \%$ confidence interval $1 \cdot 1$ to $9 \cdot 5$ ), whereas the odds ratio was $0.2(0.1$ to 0.7$)$ when comparing survival of grafts in patients positive and negative for aluminium. Neither dialysis nor transfusion influenced the rejection rate (odds ratio for dialysis $0.9(0.2$ to 3.2$)$, for transfusion $0.6(0.2$ to $2 \cdot 0)$ ).

\section{Discussion}

Our study confirms previous reports of a high prevalence of aluminium accumulation in patients with end stage renal failure. ${ }^{1011}$ To our knowledge this is the first report of aluminium accumulation and the clinical course after transplantation.

Rejection episodes occurred less commonly in patients with aluminium accumulation irrespective of age, histocompatibility matching, and transfusion and dialysis state before transplantation. These findings are compatible with a hypothesis that subclinical and clinical aluminium toxicity suppresses the alloimmune response.

Although a lower rejection rate in patients with aluminium accumulation did not result in significantly improved survival of grafts in our small series, a differential prevalence of aluminium accumulation in various subgroups may confound analysis of factors influencing prognosis in large populations. For example, blood transfusions before transplantation were found in most studies during the 1970s and early 1980 s to enhance survival of grafts, ${ }^{12-15}$ but the effect was never clearly understood and seems to have vanished in recent years. ${ }^{61516}$ During the 1980 s aluminium toxicity has been greatly reduced in patients with end stage renal failure after correction of its main causesnamely, contamination of the dialysis fluid with aluminium and use of phosphate binders containing aluminium. ${ }^{718}$ Prolonged treatment by dialysis increases the risk of aluminium accumulation, ${ }^{19}$ patients receiving dialysis require more transfusions, and sensitisation induced by transfusion prolongs the waiting (and dialysis) time before transplantation. ${ }^{13}$ Thus we propose that some of the controversies regarding the influence on prognosis of transfusions and dialysis before transplantation can be explained by the immunosuppressive effect of aluminium accumulation.

1 Alfrey AC, Le Gendre (iR, Kaehny WD. The dialysis encephalopathy syndrome: possible aluminum intoxication. $N$ Engl f Med 1976;294: 184-8.

2 Parkinson I, Ward $M 1$ Kerr D. Dialysis encephalopathy, bone disease and anaemia: the aluminium intoxication syndrome during regular haemoanaemia: the aluminium intoxication
dialysis. F Clin Pathol 1981;34:1285-94.

3 Boyce BF, Fell GS, Elder HY, et al. Hypercalcaemic osteomalacia due to aluminium toxicity. Lancet 1982;ii:1009-13.

4 Wills MR, Savory J. Aluminium poisoning: dialysis encephalopathy, osteomalacia, and anaemia. Lancet 1983;ii:29-34

5 Alfrey AC. The toxicity of the aluminium burden. Semin Nephrol 1983;3 329-34

6 Lundgren G, Groth CG, Albrechtsen D, et al. HLA-matching and pretransplant blood transfusions in cadaveric renal transplantation - a changing picture with cyclosporin. Lancet 1986;ii:66-9.

7 Maloney NA, Ot SM, Alfrey AC, Miller NL, Coburn JW, Sherrard DJ. Histological quantitation of aluminum in iliac bone from patients with renal failure. F Lab Clin Med 1982;99:206-16.

8 Dunstan CR, Evans RA. Aluminum and renal bone disease in Australia. Kidney Int [Suppl] 1986; 18:65-9.

9 Payne CD, ed. The GLIM system manual. Release 3.77. Oxford: Numerical Algorithms Group, 1987.

10 Ot SM, Maloney NA, Coburn JW, Alfrey AC, Sherrard DJ. The prevalence of bone aluminum deposition in renal osteodystrophy and its relation to the response to calcitriol therapy. $N$ Engl F Med 1982;307:709-13.

11 Smith AJ, Faugère MC, Abreo K, Fanti P, Julian B, Malluche HH. Aluminium-related bone disease in mild and advanced renal failure: evidence for high prevalence and morbidity and studies on etiology and diagnosis. Am J Nephrol 1986;6:275-83.

12 Opelz G, Dharmendra PS, Sengar DPS, Mickey MR, Terasaki PI. Effect of blood transfusions on subsequent kidney transplant. Transplant Proc 1973;5:253-9.

13 Solheim BG. The role of pretransplant blood transfusions. Transplant Proc 1979;11:138-44

14 Cats S, Terasaki PI, Perdue S, Mickey MR. Effect of HLA typing and transfusions of cyclosporine-treated renal allograft recipients. $N$ Engl F Med 1984;311:675-6.

15 Opelz $\mathbf{G}$ (for the Collaborative Transplant Study). Improved kidney graft survival in nontransfused recipients. Transplant Proc 1987;19:149-52.

16 Anonymous. Time to abandon pre-transplant blood transfusions? [Editorial] Lancet 1988;i:567-8.

17 Platts $M M$, Owen G, Smith S. Water purification and the incidence of fractures in patients receiving home dialysis supervised by a single centre: evidence for "safe" upper limit of aluminium in water. Br Med $\mathcal{J}$ 1984;288:969-72.

18 Hercz G, Andress DL, Nebecker HG, Shinaberger JH, Sherrard DJ, Coburn JW. Reversal of aluminum-related bone disease after substituting calcium carbonate for aluminum hydroxide. Am $\mathcal{F}$ Kidney Dis 1985;6:342-7.

19 Hodsman AB, Sherrard DJ, Alfrey AC, et al. Bone aluminum and histomorphometric features of renal osteodystrophy. $\mathcal{f}$ Clin Endocrinol Metab 1982;54:539-46.

(Accepted 12 October 1988 